\title{
АНАЛИЗ МИКРОФЛОРЫ И ФУНКЦИОНАЛЬНЫХ ПРОБИОТИЧЕСКИХ СВОЙСТВ ВЕРБЛЮЖЬЕГО МОЛОКА И ПРОДУКТОВ НА ЕГО ОСНОВЕ
}

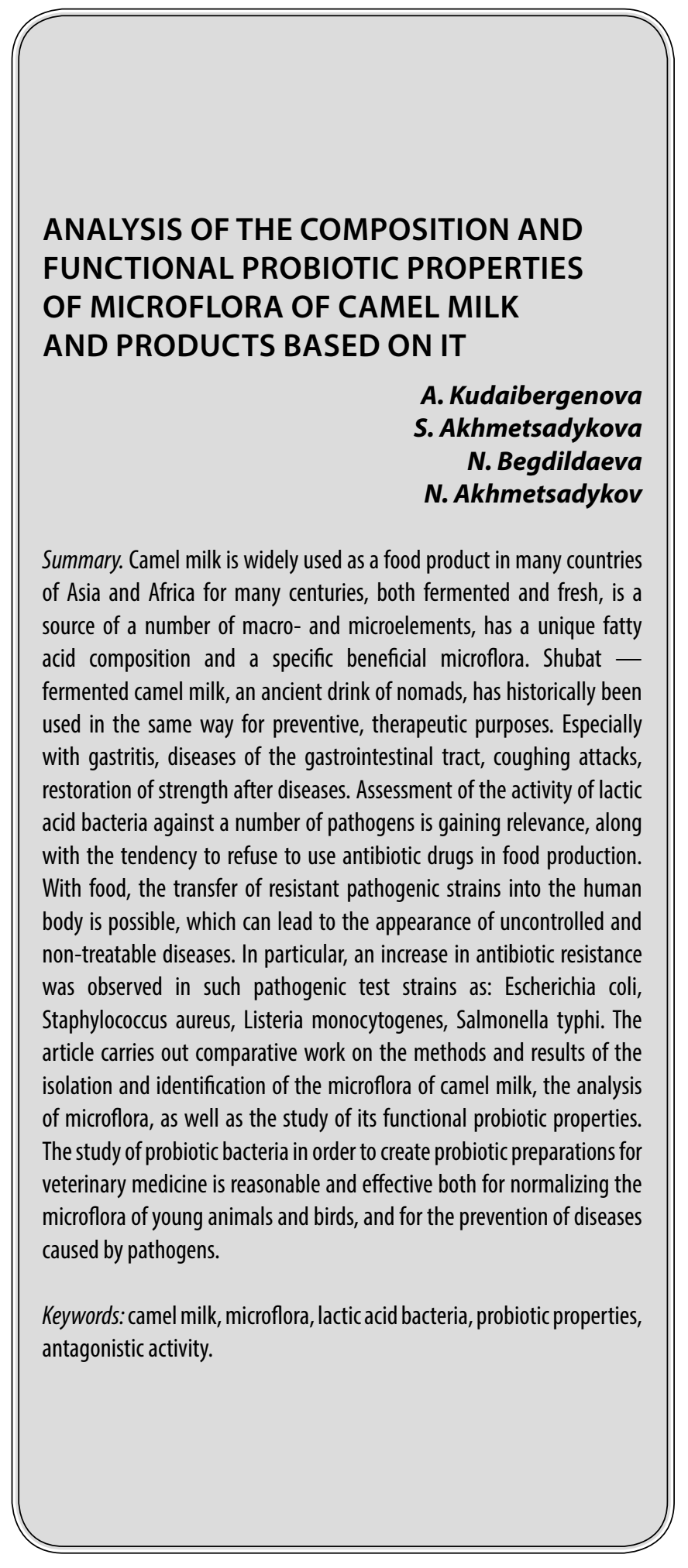

\author{
Кудайбергенова Алия Камаловна \\ Докторант, Казахский национальный университет \\ им. Аль-Фараби Алматы, Казахстан \\ alia93.20@mail.ru \\ Ахметсадыкова Шынар Нурлановна \\ $\mathrm{PhD}$, Научно-производственное предприятие \\ «Антиген», Алматинская область, Казахстан \\ shynar.akhmetsadykova@gmail.com \\ Бегдильдаева Назерке Жумановна \\ Докторант, Алматинский Технологический \\ Университет, Алматы, Казахстан \\ nzhumankyzy@mail.ru \\ Ахметсадыков Нурлан Нуролдинович \\ Д.вет.н., профессор, президент, Научно- \\ производственное предприятие «Антиген», Алматы, \\ Казахстан \\ nurlan.akhmetsadykov@gmail.com
}

Аннотация. Верблюжье молоко широко используется в качестве продукта питания во многих странах Азии и Африки на протяжении веков, как в ферментированном, так и в свежем виде, является источником ряда макро- и микроэлементов, обладает уникальным жирно-кислотным составом и специфической полезной микрофлорой. Шубат - ферментированное верблюжье молоко, древний напиток кочевников, исторически использовался так же и в профилактических, терапевтических целях. Особенно при гастритах, заболеваниях желудочно-кишечного тракта, приступах кашля, восстановлении сил после перенесенных заболеваний. Оценка активности молочнокислых бактерий в отношении ряда патогенов, приобретает свою актуальность, наряду с тенденцией отказа использования антибиотических препаратов в производстве пищевой продукции. С пищевыми продуктами возможен перенос устойчивых патогенных штаммов в организм человека, что может привести к появлению неконтролируемых и не поддающихся лечению заболеваний. Рост антибиотикорезистентности наблюдался у таких патогенных тест-штаммов, как: Escherichia coli, Staphylococcus aureus, Listeria monocytogenes, Salmonella typhi. В статье проводится сравнительная работа по методам и результатам выделения и идентификации микрофлоры верблюжьего молока, анализу микрофлоры, а так же изучению ее функциональных пробиотических свойств. Изучение пробиотических бактерий с целью создания пробиотических препаратов для ветеринарии, является обоснованным и эффективным как для нормализации микрофлоры молодняка и птиц, так и для профилактики заболеваний, вызванных патогенами.

Ключевые слова: верблюжье молоко, микрофлора, молочнокислые бактерии, пробиотические свойства, антагонистическая активность. 


\section{Введение}

B ерблюжье молоко и ферментированные продукты на его основе, рассматриваются как стратегически ценный пищевой продукт, особенно в странах засушливого климата. Помимо этого, оно является источником для выделения потенциальных пробиотических штаммов, которые могут использоваться в производстве пробиотических препаратов как для животноводства, так и для людей. По биохимическим показателям верблюжье молоко обладает, богатым белковым составом, обогащенным лизоцимами и лактоферринами, витаминами, макро и микроминералами, такими как цинк, медь и железо и высоким содержанием длинноцепочечных жирных кислот, таких как миристиновая, миристолеиновая, пальмитиновая, пальмитолеиновая, стеариновая, олеиновая, и линолевая [6]. Бактерицидные свойства верблюжьего молока представлены содержанием лактопероксидаз, лизозимов, а так же лактоферринов. Лактоферрины - железосодержащие белки, обладающие бактерицидным и противовирусным качеством, даже в отношении вируса гепатита В. Количество лактоферинов в верблюжьем молоке и их эффективность выше, нежели чем в коровьем. По целебным свойствам имеются данные о пользе ферментированного верблюжьего молока (шубата) в отношении орто- и парамиксовирусов, предположительно из-за содержания сиаловых конъюгатов и продуктов жизнедеятельности молочнокислых бактерий (МКБ) [4]. Изучение пробиотических свойств микроорганизмов, на сегодняшний день получило широкое распространение, но не утратило актуальности. Препараты на основе МКБ используются для лечения и профилактики заболеваний, связанных с разнообразными формами нарушения состава нормальной микрофлоры желудочно-кишечного тракта благодаря их антагонистической способности воздействия на патогенные микроорганизмы.

МКБ - представляют собой группу неспоровых, грамположительных бактерий, производящих молочную кислоту в качестве основного продукта ферментации. Наиболее широкоизвестны среди них, представители родов Lactobacillus, Lactococcus, Enterococcus, Bifidobacterium. Пробиотики определяются как жизнеспособные микроорганизмы, которые могут оказывать различное благотворное влияние на хозяина при приеме внутрь определенной концентрации. Среди полезных эффектов пробиотиков можно выделить их антипатогенное, антиканцерогенное и антимутагенное действие, а так же удаление избыточного холестерина и облегчение симптомов непереносимости лактозы [11]. Пробиотики, применяются для коррекции микрофлоры желудочно-кишечного тракта человека и сельскохозяйственных животных, с целью профилактики дисбактериозов, вызванных такими патогенными микроорга- низмами, как: Staphyllococcus aureus, Esherichia coli, Salmonella typhimurium и другими [15].

Задача данной статьи заключается в сравнении выделенной микрофлоры верблюжьего молока, изучении ее функциональных пробиотических свойств, а также сопоставлении экспериментальных данных полученных из отдаленных друг от друга регионов с различными климатическими местностями обитания.

Материалы и методы исследования Согласно множественным исследованиям, первый этап - это выделение молочнокислых бактерий. Проводят его путем разведения молока растворе $\mathrm{NaCl}$ (8,5 г/л) и последующих разведений до $10^{-8}$. Далее осуществляют посев на чашки Петри с плотными селективными питательными средами для лактобацилл. По окончанию инкубации, отбирают морфологически подходящие колонии для дальнейших тестов $[5,9,12]$. Предпочтительная среда для выращивания МКБ поддерживающая их хороший рост - MRS. Coдержит полисорбат TWIN-80, ацетат, магний, марганец, которые действуют как специфические факторы роста МКБ, а так же богатую питательную основу [9].

Выращенные культуры МКБ на селективных средах, проходят морфологический скрининг, который включает описание формы, размеров, окраску по граму. Штаммы МКБ должны быть круглыми, неспорообразующими, грамположительными, каталазно- и оксидазно-отрицательными факультативными анаэробами $[5,9,12]$.

Видовая идентификация микроорганизмов осуществляется при помощи изучения полимеразно-цепной реакции, с предварительной экстракцией ДНК методом рPHК-16S [12]. Суть, которого заключается в филогенетической классификации штамма. Ген рPHК-16S используется в качестве стандарта для классификации и идентификации микроорганизмов.

Далее проводится ряд анализов на изучение пробиотического потенциала МКБ. Оцениваются физико-химические свойства, такие как жизнеспособность в температурных условиях ЖКТ, при пониженной кислотности. Результаты фиксируются подсчетом количества выживших клеток. Аналогично проверяется устойчивость к условиям пищеварительного тракта и ферментам проверяют in vitro, добавляя в среду с МКБ желчные соли, панкреатин и ферменты - пепсин, трипсин, устойчивость к антибиотикам. Антагонистическое действие пробиотических микроорганизмов измеряется методом лунок. О способности МКБ задерживать и останавливать рост патогенных индикаторных штаммов судят по расстоянию зоны ингибирования [14]. Для оценки адгезивности МКБ in vitro используют эукариотичекие клетки или пластины из нержавеющей стали. Метод заключа- 
Таблица 1. Видовой состав микрофлоры верблюжьего молока

\begin{tabular}{|c|c|c|}
\hline Географическая местность & $\begin{array}{l}\text { Видовой состав микрофлоры и его процентное } \\
\text { содержание }\end{array}$ & Источник \\
\hline Кувейт (2019 г.) & $\begin{array}{l}\text { Enterococcus spp. (24.2\%), Lactococcus spp. } \\
\text { (22.4\%), Pediococcus spp. (20.7\%), Weissella } \\
\text { spp. (10.3\%) }\end{array}$ & R. Rahmeh и др. [11]. \\
\hline Китай (провинция Сиань, 2009 г.) & $\begin{array}{l}\text { Lactobacillus spp.(44\%), Enterococcus spp. } \\
(19 \%), \text { Leuconostoc spp. (10\%), Weissella spp. } \\
(3 \%)\end{array}$ & N. Rahman и др. [12]. \\
\hline Египет (2013 г.) & $\begin{array}{l}\text { Enterococcus spp. (81.6\%), Lactococcus spp. } \\
\text { (9\%), Lactobacillus spp. (9\%), Aerococcus } \\
\text { viridans spp. }(9 \%)\end{array}$ & E. Hamed, A. Elattar [7]. \\
\hline Казахстан (2015 г.) & $\begin{array}{l}\text { Enterococcus spp. (51.3\%), Lactococcus spp. } \\
\text { (10.9\%), Lactobacillus spp. (29.8\%), Leuconostoc } \\
\text { spp. (8\%) }\end{array}$ & Akhmetsadykova et al. [1]. \\
\hline
\end{tabular}

Таблица 2. Тест-штаммы возбудителей заболеваний

\begin{tabular}{|c|c|c|}
\hline Патогенный тест-штамм & Классификационный номер & Заболевание \\
\hline Salmonella enterica & ATCC13076 & Сальмонеллез \\
\hline Escherichia coli & ATCC25922 & кишечные расстройства \\
\hline Staphylococcus aureus & ATCC25923 & инфекции кожных покровов, эндокардит \\
\hline Staphylococcus epidermidis & ATCC12228 & $\begin{array}{l}\text { возбудитель сепсиса, эндокардита, } \\
\text { конъюнктивита, гнойной инфекции ран }\end{array}$ \\
\hline Listeria monocytogenes & ATCC7644 & возбудитель листериоза \\
\hline Shigella flexneri & ATCC12022 & расстройства ЖКТ, шигеллез \\
\hline Pseudomonas aeruginosa & ATCC27853 & возбудитель нозокомиальных инфекций \\
\hline
\end{tabular}

ется в следующем, после посева и выдержки в течение суток МКБ на пластине или клеточном слое, его промывают несколько раз, в последующем оценивают процент адгезированных клеток [8-9,14].

\section{Результаты \\ исслеАований микрофлоры \\ и ее пробиотических свойств}

По данным обзора результатов исследований, наиболее распространенные штаммы МКБ, обладающие пробиотическими свойствами представлены родом Lactobacillus spp., включая следующие виды - Lb. acidophilus, Lb. johnsonii, Lb. casei, Lb. rhamnosus, Lb. gasseri, and Lb. reuteri., а так же Lactococcus spp., например, Lactococcus lactis [3].

В приведенных исследованиях микрофлоры верблюжьего молока и молочных продуктов (табл. № 1), прослеживается содержание наиболее часто встречаемых групп микроорганизмов, таких как: Lactococcus spp., Enterococcus spp., Lactobacillus spp.- которые наблюдаются и в параллельных исследованиях. Выделение и изучение основных видов состава микрофлоры
МКБ в различных географических местностях представлены в следующей таблице:

При оценке пробиотических свойств данных микроорганизмов, по данным [12], общее среднее количество МКБ в шубате колеблется в диапазоне 6,8-7,6 KOE/ мл, при этом рН равен 3,7-4,1. В опытах [2] указано что наилучшей устойчивостью к пониженной кислотности обладают E. durans, L. casei, E. lactis, P. pentosaceus, $W$. cibaria, к желчным солям максимально устойчивы $E$. durans, E. faecium, L. casei, P. pentosaceus, чуть менее устойчивым штаммом оказался E. lactis, выживаемость которого составила более 50\% после шестичасового выдерживания в 0,4\% растворе желчных солей [2].

Как уже упоминалось, немаловажную роль в оценке пробиотического потенциала играет способность МКБ оказывать угнетающее действие на особо распространенные штаммы бактерий, вызывающих нарушение естественной микрофлоры организма, а так же являющихся болезнетворными.

Среди представленных в таблице № 2 штаммов возбудителей, стоит выделить наиболее распространен- 
Таблица 3. Сравнительные данные величин зоны ингибирования МКБ и бифидобактерий выделенных из верблюжьего молока

\begin{tabular}{|c|c|c|c|c|c|}
\hline Штамм & E.coli & S. aureus & L. monocy-togenes & S.typhim-rium & Источник \\
\hline $\begin{array}{l}\text { 1. Pediococcus } \\
\text { acidilactici }\end{array}$ & $35.0 \pm 2.0$ & $34.3 \pm 2.0$ & $34.0 \pm 0.0$ & Нет данных & \multirow{3}{*}{ R. Rahmeh, 2009 г. } \\
\hline 2.Lactobacillus reuteri & $30.0 \pm 0.0$ & $46.0 \pm 0.0$ & $33.0 \pm 1.0$ & Нет данных & \\
\hline 3. Enterococcus durans & $29.0 \pm 2.0$ & $27.0 \pm 2.0$ & $35.0 \pm 1.0$ & Нет данных & \\
\hline 4. Lactococcus lactis & Нет данных & $30.0 \pm 1.0$ & Нет данных & $33.0 \pm 1.0$ & \multirow{2}{*}{$\begin{array}{l}\text { H.Eman, A. Elattar, } \\
2013 \text { г. }\end{array}$} \\
\hline $\begin{array}{l}\text { 5. Enterococcus } \\
\text { faecium }\end{array}$ & Нет данных & $33.0 \pm 1.0$ & Нет данных & $38.0 \pm 1.0$ & \\
\hline $\begin{array}{l}\text { 6. Lactobacillus } \\
\text { plantarum }\end{array}$ & $17.3 \pm 0.5$ & $17.00 \pm 1.0$ & $19.00 \pm 1.0$ & $18.6 \pm 0.5$ & \multirow{3}{*}{ G. Mulaw et.al, 2019 г. } \\
\hline $\begin{array}{l}\text { 7. Lactobacillus } \\
\text { paracasei subsp. } \\
\text { tolerans }\end{array}$ & $20.6 \pm 0.5$ & $20.3 \pm 1.1$ & $19.6 \pm 0.5$ & $19.6 \pm 0.5$ & \\
\hline $\begin{array}{l}\text { 8. Lactobacillus } \\
\text { paracasei }\end{array}$ & $20.0 \pm 1.0$ & $20.3 \pm 0.5$ & $19.6 \pm 0.5$ & $18.3 \pm 0.5$ & \\
\hline $\begin{array}{l}\text { 9. Bf. longum subsp. } \\
\text { longum B- } 11\end{array}$ & $14 \pm 0.1 \mathrm{MM}$ & $11 \pm 0.3 \mathrm{Mm}$ & Нет данных & $12 \pm 0.1 \mathrm{Mm}$ & I. Yasmin et.al, 2020 г. \\
\hline
\end{tabular}

ные - Escherichia coli, Staphylococcus aureus, Listeria monocytogenes, Salmonella typhi $[1,7,9]$. Так, по данным E. Etadati (2019), наиболее высокую антагонистическую активность в отношении Staphylococcus aureus и Echerichia coli, среди выделенных из МКБ верблюжьего молока, демонстрируют Leuconostoc mesenteroides, Lactobacillus plantarum [11]. В аналогичном исследовании, антагонистическая активность МКБ исследовалась в отношении Salmonella typhimurium, E. coli и Vibrio fluvialis. Полученные результаты, указывают на то, что наиболее высокая антагонистическая активность выражена у: Enterococcus faecium зона ингибирования выражена в миллиметрах, соответственно [10]. Другие штаммы МКБ, так же показывают хорошую антагонистическую активность: Lactococcus lactis subsp. cremoris u Lactobacillus plantarum. Составлена сравнительная таблица ценных пробиотических штаммов, выделенных из верблюжьего молока, различными учеными группами, отражает зону ингибирования в миллиметрах.

По данным таблицы № 3, Pediococcus acidilactici, оказывает максимальное антибактериальное воздействие на рост кишечной палочки, Lactobacillus reuteri ингибирует рост золотистого стафилококка, бактерии рода Enterococcus (в частности Enterococcus durans, Enterococcus faecium) хорошо подавляют и препятствуют развитию патогенов Listeria monocytogenes, Salmonella typhimurium. Помимо основных представителей МКБ, верблюжье молоко богато и бифидобактериями, так же обладающих пробиотическим потенциалом. Среди представителей рода Bifidobacteria встречаются-Bf. bifidum, Bf. animalis subsp. lactis, Bf. longum subsp. Longum и Bf. longum subsp. infantis [15].
По результатам I. Yasmin [15] с соавторами, Bf. longum subsp. longum B-11, демонстрирует наилучшие функциональные пробиотические свойства, к примеру: выживаемость в условиях $\mathrm{pH}=2$ составляет около 85\%; высокий процент гидрофобности клеточной поверхности к ксилену, около 78\%, что имеет значение в процессе агрегации; отсутствие гемолитической активности; способность к росту при различных температурных режимах (от $10-45^{\circ} \mathrm{C}$ ) и другие. Таким образом, Bf. longum subsp. longum B-11 выделенный из верблюжьего молока, так же способен оказывать большее ингибирующее действие на рост и развитие бактериальных патогенов.

\section{Зак^ючение и вывоАы}

Перспективы подробного изучения микрофлоры верблюжьего молока и продуктов на его основе имеют основания считаться актуальными. В мировом пространстве было проведено мало полноценных исследований функциональных пробиотических свойств МКБ верблюжьего молока, однако полученные данные подтверждают, что его микрофлора является уникальным источником пробиотических штаммов например, таких как: Pediococcus acidilactici, Lactobacillus reuteri, Enterococcus durans, Enterococcus faecium, Lactobacillus plantarum, Lactobacillus paracasei, Bf. longum subsp. longum и другие.

Таким образом, прослеживается и практическая значимость исследования в виде возможности разработок пробиотического препарата для животноводства на основе МКБ выделенных из верблюжьего молока и его продуктов. 


\section{ЛИТЕРАТУРА}

1. Akhmetsadykova S., Baubekova A., Konuspayeva G., Akhmetsadykov N., Faye B. Loiseau G. Lactic acid bacteria biodiversity in raw and fermented camel milk / S. Akhmetsadykova, A. Baubekova, G. Konuspayeva, N. Akhmetsadykov, B. Faye, G. Loiseau // African Journal of Food Science and Technology-2015.-Vol. 6 — P. 84-88

2. Davati N. Study of Lactic Acid Bacteria Community From Raw Milk of Iranian One Humped Camel and Evaluation of Their Probiotic Properties/ N. Davati, F. Tabatabaee Yazdi, S. Zibaee, F. Shahidi, MR. Edalatian // Jundishapur J Microbiol. — 2015; Vol. 2015, No. 8. - 14 pages. D0l:10.5812/jjm.8(5)2015.16750

3. Chelliaha RInvitro and invivo defensive effect of probiotic LABagainstPseudomonas aeruginosa using Caenorhabditis elegansmodel/R. Chelliaha,J. Choia, S. Hwanga, B. Parka, E. Daliria, S. Kima, S. Weib, R. Ramakrishnanc, D. Oha // Virulence — 2018. — Vol. 9, No. 1. — P. 1489-1507. D0I: 10.1080/21505594.2018.1518088

4. Chuvakova Z. Chemical composition, microbial control and antiviral properties of freshly made and conserved Shubat "Bota" Z. Chuvakova, R. Beisembayeva, 0. Puzyrevskaya, M. Saubenouva, M. Shamenova, T. Glebova, E. Popova, M. Baizhomartova, E. Baimenov // In: Park YW (ed) Bioactive components in milk and dairy products. Wiley, Hoboken- 2009.-Vol. 266, P. 171-172

5. Edalati E. Isolation of probiotic bacteria from raw camel's milk and their antagonistic effects on two bacteria causing food poisoning / E. Edalati, B. Saneei, M. Alizadeh, S. Hosseini, A. Zahedi Bialvaei, and K. Taheri

6. Farah Z, Streiff T., Bachmann M. R. 1989. Manufacture and characterization of camel milk butter. Milchwissenschaft 44:412-414

7. Hamed E. and Elattar A. Identification and Some Probiotic Potential of Lactic Acid Bacteria Isolated From Egyptian Camels Milk/ E. Hamed, A. Elattar.// Life Science Journal- 2013. - Vol. 10, No. 1.P. 1953-1966.

8. Monteiro C. In Vitro Antimicrobial Activity and Probiotic Potential of Bifidobacterium and Lactobacillus against Species of Clostridium/ C. Monteiro, S. Monique, 0. Bruna, S. Matheus, C. Santos, S. Maria Rosa Q. Bomfim, E. Fernandes and V. Monteiro-Neto // Nutrients - 2019. Vol. 448. No. 11. - 16 pages. D0l:10.3390/ nu11020448

9. Mulaw G. In Vitro Evaluation of Probiotic Properties of Lactic Acid Bacteria Isolated from Some Traditionally Fermented Ethiopian Food Products / G. Mulaw, T. S. Tessema, D. Muleta and A. Tesfaye // Hindawi International Journal of Microbiology-2019.-Vol. 2019-8 pages. D0l: 10.1155/2019/7179514

10. Ouwehand A. Probiotics: an overview of benefical effects/ A. C. Ouwehand, S. Salminen, E. Isolauri // Antonie Van Leeuwenhoek- 2002. - Vol. 82, No. 1-4, P. 279_ 289.

11. Quigley E. Prebiotics and Probiotics in Digestive Health / Quigley E. // Clin. Gastroenterol. Hepatol — 2019. Vol. 362, No. 2. - P. 333-344. D0l: 10.1016/j. cgh.2018.09.028.

12. Rahman N. Characterization of the dominant microflora in naturally fermented camel milk shubat/ N. Rahman, V. Xiaohong, F. Meiqin, D. Mingsheng // World J Microbiol Biotechnol -2009.—Vol.25 No. 17.—P. 1941-1946. D0l: 10.1007/s11274-009-0092-5

13. Rahmeh R. Distribution and antimicrobial activity of lactic acid bacteria from raw camel milk/ R. Rahmeh, A. Akbar, M. Kishk, T. Al-Onaizi, A. Al-Azmi, A. Al-Shatti, A. Shajan, S. Al-Mutairi and B. Akbar New Microbes and New Infections — 2019.— Vol. 30, No. 1. — 8 pages. D0I: 10.1016/j.nmni.2019.100560.

14. Ren D. Antimicrobial Characteristics of Lactic Acid Bacteria Isolated from Homemade Fermented Foods/ D. Ren, J. Zhu, S. Gong, H. Liu, H. Yu// Hindawi BioMed Research International -2018. — Vol. 2018, No.4. — 9 pages. D0I: 10.1155/2018/5416725

15. Yasmin I. In vitro Probiotic Potential and Safety Evaluation (Hemolytic, Cytotoxic Activity) of Bifidobacterium Strains Isolated from Raw Camel Milk / I. Yasmin, M. Saeed, W. Ali Khan, A. Khaliq, M. Chughtai, R. qbal, S. Tehseen, S. Naz, A. Liaqat, T. Mehmood, S. Ahsan and S. Tanweer // Microorganisms 2020. Vol. 354, No. 8. 21 pages. D0I:10.3390/microorganisms8030354.

( Кудайбергенова Алия Камаловна ( alia93.20@mail.ru ), Ахметсадыкова Шынар Нурлановна ( shynar.akhmetsadykova@gmail.com ), Бегдильдаева Назерке Жумановна ( nzhumankyzy@mail.ru ), Ахметсадыков Нурлан Нуролдинович ( nurlan.akhmetsadykov@gmail.com ). Журнал «Современная наука: актуальные проблемы теории и практики» 